\title{
Analysis on Innovation Strategy of Logistics Management in E-commerce Environment
}

\author{
Chunbin Liu ${ }^{1, \text { a }}$ \\ 'Jiangxi University Of Applied Science,Nanchang,Jiangxi,China,330100 \\ a1790596477@qq.com
}

\begin{abstract}
The development of e-commerce has provided a lot of help for the development of logistics industry in China, and with the development of this era, the logistics industry in China is making continuous progress. And the method and content of innovative logistics management is very important in the current context of e-commerce, because only by innovating the method and content of logistics management can we improve the level of logistics management and make logistics management and e-commerce achieve a better integration. This paper mainly focuses on the innovation strategy of logistics management in e-commerce environment.

Keywords: E-commerce; Logistics management; Innovation
\end{abstract}

\section{电子商务环境下的物流管理创新策略分析}

刘春斌 ${ }^{1, a}$

${ }^{1}$ 江西应用科技学院, 南昌, 江西, 中国, 330100

a1790596477@qq.com

\section{摘要}

电子商务的发展为我国物流行业的发展提供了非常多的助力, 而随着这个时代的发展, 我国物流行业 在不断的进步中。而创新物流管理的方法和内容在当前的电子商务背景下是非常重要的，因为只有通 过创新物流管理的方法和内容，才能够提高物流管理的水平，也才能够使物流管理和电子商务达到更 好的融合。而本文就主要围绕电子商务环境下的物流管理创新策略进行研究和探讨。

关键词: 电子商务; 物流管理; 创新

\section{1. 物流管理创新内涵与概念}

物流管理在电子商务环境下的管理方式是以电子 商务模式为具体背景, 以此为运营和操控的平台, 利用 现代信息技术，对企业的生产、销售等环节采取一站式 管理，通过最简便、最直观的方式对整个过程进行控制， 将传统的物流管理模式打破。

电子商务环境下的物流管理模式需要更广泛地收 集客户需求信息, 并能够对所获得的信息做出良好的采 购预测。同时, 要与企业保持沟通与交流, 确定库存数 量地点和订单数量的优化方案, 实现物流跟踪与库存的 有效协调, 减少流通中的库存量, 其中主要包括库存管 理、仓库管理和运输管理多个方面。其中, 库存管理就 是采取最合理的方式达到库存与服务的平衡点, 建立最 合理的管理模式, 管理模式可以确定企业的具体压力状 况。如果商品在周转期太频繁, 预存商品太多, 那么利 润可能会减少。仓储管理也是物流的重要组成部分, 它 部署各个系统, 包括位置的安排、选择、接收和交付货
物等，在此过程中，必须注意质量管理。运输管理的主 要内容是确定运输方式、路线、计划和运输中的装载量、 运输时间的分配，以及运输方式的具体安排等。最合理、 最优的安排是积极利用现有资源, 充分发挥运输手段, 通过对合理时间内的状况进行保障，完成送货的需求。

\section{2. 电子商务环境下的物流管理特点与模式}

\section{1 电子商务环境下的物流管理特点}

在电子商务环境下，实现信息网络化是物流管理的 必然趋势。在供应链管理中, 物流管理需要全面频繁交 换物流信息, 为了实现整个物流供应链的对接, 通常以 交易凭证的交换为主要交易模式，从而转化为业务数据 交换的数字化管理，库存管理上实现零库存，周期短， 这都依赖于信息网络管理将信息灵敏地传送。物流信息 网络化管理是物流管理发展的必然趋势和要求, 在互联 网不断普及的今天，不停发展的网络技术为物流信息网 
络管理提供了良好的基础。如果物流管理信息不是基于 网络的, 那么大部分信息只能停留在企业内部, 不能与 物流信息共享，对外交流也很困难。

\section{2 电子商务环境下的管理模式}

在电子商务的自建物流系统中, 企业通常会根据其 所在的互联网密集区域设置配送点。在获得相应的购物 信息后, 可以立即到达相应的配送点, 然后配送点的工 作人员将货物送上门。在电子商务发展的具体过程中, 需要通过庞大的连锁分销渠道和零售网络来实现, 大型 物流集团通常利用电子商务技术建立自己的物流管理 系统, 从而实现物流配送。自建物流系统增强了企业的 竞争优势, 提高了物流管理和配送的效率。

契约物流是指在生产和销售过程中提供服务的第 三方, 它不生产或销售商品, 而是与企业形成合作协议 或联盟, 以提供个性化的物流服务。由于现代技术的不 断加强和配送体系的相对完善, 第三方物流具有速度快、 效率高的特点, 也是电子商务配送物流的合理解决方案 之一。大型企业往往选择建立自己的物流系统进行物流 管理, 这种契约物流更适合中小物流企业的发展, 既能 满足客户不断变化的物流需求, 又能减轻电子商务企业 的负担, 从而实现分工与合作。

\section{3. 传统物流管理模式上的主要缺陷}

\section{1 物流管理的信息化程度不高}

当前电子商务已经得到了急速的发展, 而虽然有很 多物流企业也已经开始使用电子商务的发展模式, 开始 不断的进行转型和发展, 并且甚至建立网络商务系统, 但是就现阶段而言, 很多物流企业虽然已经有了发展的 概念和发展的意识, 但是真正的发展水平却没有得到真 正意义上的提升, 而与国外的物流管理水平相比, 还有 很大的进步空间。而从积极的角度上看来, 我国的物流 管理才刚刚起步, 可以充分的借鉴国外的成功经验, 而 我国的市场也非常生机勃勃, 能够为物流管理的发展提 供更多的有利因素; 而从消极的角度看来, 我国的物流 管理水平还不足以支撑我国的信息经济的发展。而且在 我国的物流企业中，信息化概念还没有得到完全普及性， 也就是很多物流企业甚至都没有信息化建设的想法和 观念。而缺乏信息化建设理念, 则会影响到企业的可持 续发展, 也会影响到企业的进一步的经营管理。而如果 能够在物流企业中广泛的应用信息化管理手段, 那么自 然就能够提供物流企业的工作效率和工作质量。但是现 阶段而言, 在很多物流企业中, 大部分的物业管理人员 都无法熟练的使用操作系统, 这也是因为在对物流管理 人才的培养过程中, 并没有重视对物流管理人员的实践 操作能力的培养, 而由于缺乏这方面的人才, 自然也就 影响到了物流管理水平的发展。

\section{表 1 传统物流管理模式上的主要缺陷}

\begin{tabular}{|c|c|c|}
\hline $\begin{array}{c}\text { 物流管理的信息 } \\
\text { 化程度不高 }\end{array}$ & $\begin{array}{c}\text { 缺乏更多的专业 } \\
\text { 人才 }\end{array}$ & $\begin{array}{c}\text { 物流专业服务水 } \\
\text { 平比较低 }\end{array}$ \\
\hline 当前电子商务已 & 在我国的物流市 & 就现在而言, 大 \\
\hline 经得到了急速的 & 场上, 中小型企 & 部分物流企业都 \\
\hline 发展, 而虽然有 & 业的比例要远远 & 更加重视货物运 \\
\hline 很多物流企业也 & 大于大型企业, & 输和存货服务, \\
\hline 已经开始使用电 & 这是因为当前我 & 但是却不够重视 \\
\hline 子商务的发展模 & 国市民缺乏物流 & 物流的成本以及 \\
\hline 式, 开始不断的 & 管理专业人才, & 物流的信息服 \\
\hline 进行转型和发 & 所以在招聘物流 & 务, 而物流成本 \\
\hline 展, 并且甚至建 & 管理专业人才的 & 和物流信息服务 \\
\hline 立网络商务系 & 事业遇到了非常 & 都是十分重要 \\
\hline 统, 但是就现阶 & 多的困难, 很多 & 的, 尤其是物流 \\
\hline 段而言, 很多物 & 企业已经招聘招 & 信息服务, 物流 \\
\hline 流企业虽然已经 & 都的专业人才 & 信息服务和直接 \\
\hline 有了发展的概念 & 中, 大部分都仅 & 影响到客户, 对 \\
\hline 和” & 仅只是具备一方 & 于物流企业的体 \\
\hline 但是真正的发展 & 面的能力和素 & 验感受, 也影响 \\
\hline 水平却没有得到 & 质, 但是却没有 & 到物流企业在市 \\
\hline 真正意义上的提 & 具备全面的能力 & 场上的发展。 \\
\hline 升, 而与国外的 & 和综合素质, 而 & \\
\hline 物流管理水平相 & 且影响到了物流 & \\
\hline $\begin{array}{l}\text { 比, 还有很大的 } \\
\text { 进步空间。 }\end{array}$ & $\begin{array}{l}\text { 管理价值的发 } \\
\text { 挥。 }\end{array}$ & \\
\hline & & \\
\hline
\end{tabular}

\section{2 缺乏更多的专业人才}

我国的物流企业中大部分都是中小型企业, 大型企 业则较小, 只是说是因为物流企业在我国的发展才刚刚 处于基本阶段, 所以有很多企业不敢贸然发展为大型企 业, 还有一部分企业因为缺乏相应的实力和能力, 因此, 引发成为大型企业和中小型企业都发展的方向主要是 以盈利为主。但是其盈利情况远远比不上大型企业知识 创新, 物流企业的风险相对于大型物流企业而言也较小, 因此, 在我国的物流市场上, 中小型企业的比例要远远 大于大型企业, 这是因为当前我国市民缺乏物流管理专 业人才，所以在招聘物流管理专业人才的事业遇到了非 常多的困难, 很多企业已经招聘招都的专业人才中, 大 部分都仅仅只是具备一方面的能力和素质, 但是却没有 具备全面的能力和综合素质, 而且影响到了物流管理价 值的发挥。而物流管理专业人才不仅仅要具备相关物流 管理专业知识，同时还应该具备一定的实践操作能力, 还要了解更多的物流管理知识掌握更多的技能, 而这也 说明物流管理人员是高素质的复合型人才, 而物流企业 所需要的也是高素质的波形人才, 只是现阶段的员工各 种物流企业中无论是物流管理人员的数量, 还是物流管 理人员的质量都没有达到企业的需求标准。而且当前我 国物流企业的电子商务的配送体系也并不是十分完善, 在此过程中也为用户带来非常大的困扰, 而电子商务与 物流管理的结合，虽然能够帮助物流企业实现信息化， 
但是电子商务在物流企业中的融合程度还不足以推动 物流企业的发展。在至今的物流配送的情况中也可以看 出物流企业的网络作业体系仍然不够健全。

\section{3 物流专业服务水平比较低}

就现在而言, 大部分物流企业都更加重视货物运输 和存货服务, 但是却不够重视物流的成本以及物流的信 息服务, 而物流成本和物流信息服务都是十分重要的, 尤其是物流信息服务, 物流信息服务和直接影响到客户, 对于物流企业的体验感受, 也影响到物流企业在市场上 的发展, 而物流企业想要得到提升和发展, 那么物流企 业就必须实现专业化和服务化, 而所谓的服务化和专业 化, 也就是指提升物流信息服务的质量和水平, 落实相 关提升物流管理服务化水平也必须要加强对物流运输 的设计, 使物流运输设计更加合理、也更加满足用户的 期待。

\section{4. 电子商务环境下的物流管理创新策略}

\section{1 改善人才结构}

在物流管理企业中, 人才资源就是最重要的资源之 一，因为任何企业都需要人才的组成，企业才能够得以 发展和提升, 而人才资源是企业的组成与企业的发展过 程中必不可少的因素, 如果企业能够得到更多的物流管 理专业人才资源，那么企业自然就能够得到更好的发展。 而当前的物流企业所需要的是复合型的物流管理专业 人才, 专业不对口, 物流人员是难以符合企业发展需求 的。因此这要求必须要加强队伍的管理的人才结构的重 视, 尽可能的改善物流管理专业的人才结构, 培养更多 物流管理专业的人才。

\section{2 加强对物流活动的控制}

物流企业想要得到更好的经营效果, 那么物流企业 就必须要满足客户的物流需求并且充分的理解客户的 需求为客户提供个最新的物流信息, 为客户提供更好的 物流服务。而在物流管理中应用信息技术的优势也在于 信息技术能够实物的管理, 更加规划的规范化和程序化, 同时也能够使物理信息能够更加及时和便捷的传递给 用户。企业也应该加强队伍的活动的控制, 因为加强队 伍的活动控制可以提升物流活动的效率, 也能够在一定 程度上降低物流成本, 给用户提供更好的物流方案。

\section{表 2 电子商务环境下的物流管理创新策略}

\begin{tabular}{|c|c|c|c|}
\hline $\begin{array}{c}\text { 改善人才 } \\
\text { 结构 }\end{array}$ & $\begin{array}{c}\text { 加强对物流活 } \\
\text { 动的控制 }\end{array}$ & 政府积极引导 & $\begin{array}{c}\text { 引入现代化 } \\
\text { 技术 }\end{array}$ \\
\hline 在物流管 & 物流企业想要 & 作为市场和社 & 物流管理智 \\
理 企 业 & 得到更好的经 & 会的主 导力 & 能化是电子 \\
中, 人才 & 营效果, 那么 & 量, 政府应该 & 商务环境下 \\
\hline
\end{tabular}

\begin{tabular}{|c|c|c|c|}
\hline 资源就是 & 物流企业就必 & 在物流业的发 & 物流管理的 \\
\hline 最重要的 & 须要满足客户 & 展中发挥重要 & 新途径和新 \\
\hline 资 源 之 & 的物流需求并 & 作用。要完善 & 方向, 物流 \\
\hline 一，因为 & 且充分的理解 & 物流管理的相 & 管理需要智 \\
\hline 任何企业 & 客户的需求为 & 关法律法规, & 能化技术, \\
\hline 都需要人 & 客户提供个最 & 明确政府在市 & 引进国外先 \\
\hline 才的 组 & 新的物流信 & 场中的具体功 & 进技术可以 \\
\hline 成, 企业 & 息, 为客户提 & 能, 促进物流 & 为物流管理 \\
\hline 才能够得 & 供更好的物流 & 管理的规范 & 和创新提供 \\
\hline 以发展和 & 服务。 & 化、系统化。 & 相应的基础 \\
\hline 提升, 而 & & & 物流 \\
\hline 人才资源 & & & 智能化管理 \\
\hline 是企业的 & & & 已成为电子 \\
\hline 组成与企 & & & 商务环境下 \\
\hline 业的发展 & & & 物流管理的 \\
\hline 过程中必 & & & 一个重要方 \\
\hline 不可少的 & & & \\
\hline & & & \\
\hline
\end{tabular}

\section{3 政府积极引导}

作为市场和社会的主导力量，政府应该在物流业的 发展中发挥重要作用。首先要完善物流管理的相关法律 法规, 明确政府在市场中的具体功能, 促进物流管理的 规范化、系统化。同时，政府应该提出相应的管理机制 来引导和促进物流的发展, 使各部门能够得到有效的协 调, 进一步加强政府在物流管理方面的力度, 从而促进 物流业的发展。

\section{4引入现代化技术}

物流管理智能化是电子商务环境下物流管理的新 途径和新方向, 物流管理需要智能化技术, 引进国外先 进技术可以为物流管理和创新提供相应的基础支持。物 流智能化管理已成为电子商务环境下物流管理的一个 重要方向。因此, 为了物流管理的需求, 就要不断引进 现代技术, 实现现代化操作的存储、批发与物流管理。 同时, 积极地引入智能化运行、借助专家系统、利用人 工智能操作系统, 不断解决物流管理中存在的问题, 使 电子商务环境下的物流管理可以获得足够的技术支持。

\section{5. 结语}

就现在而言, 我国的物流行业在电子商务背景下已 经得到了急速的发展，但是不可避免的是在其中也有很 多问题存在, 为了解决这些问题, 我们就必须加强对物 流管理的重视, 并且不断探索有效的提升物流管理水平 的路径。 


\section{References}

[1] Luxue. Research on Innovation Strategy of Logistics Management in E-commerce Environment[J]. Economic research guide. 2019(04)

[2] Xiaona Mou. Analysis on Innovation Path of Tea Logistics Management in E-commerce Environment[J]. Fujian tea. 2018(12)

[3] Yijin Zhao. Logistics Management Status and Innovation Strategies under Electronic Commerce[J]. Chinese and foreign entrepreneurs. 2018(36)

[4] Zhaoqiang. Innovation Strategy of Logistics Management Based on Electronic Commerce[J]. Taxes. 2018(26)

[5] Huangman. Exploration on Innovation Strategy of Logistics Management in E-commerce Environment[J]. Oriental corporate culture. 2018(S2)
[6] Chungen Xu. Research on Innovation of Logistics Management Mode in E-Commerce Environment[J]. Chinese and foreign entrepreneurs. 2018(26)

[7] Junnuan Lin. Research and Analysis on the Development Path of Logistics Management Innovation in E-commerce Environment[J]. The Think Tank Age. 2018(29)

[8] Junjun cai. On the Innovation Strategy of Logistics Management in E-commerce Environment[J]. Chinese and foreign entrepreneurs. 2018(08)

[9] Duyu. Research on Innovation Development Path of Logistics Management in E-commerce Environment[J]. Modern economic information. 2018(01)

[10] Wanda Hu. Research on Modern Logistics Management Innovation Based on E-Commerce[J]. Quality Exploration. 2016(04) 